\title{
$P$. aeruginosa colonization at ICU admission as a risk factor for developing $P$. aeruginosa ICU pneumonia
}

\author{
Fleur P. Paling ${ }^{1 *}$, Martin Wolkewitz ${ }^{2}$, Pieter Depuydt ${ }^{3}$, Liesbet de Bus ${ }^{3}$, Frangiscos Sifakis ${ }^{4}$, Marc J. M. Bonten ${ }^{1,5}$
} and Jan A. J. W. Kluytmans'

\begin{abstract}
Objective: To determine the incidence of P. aeruginosa (PA) ICU pneumonia and its independent association with PA colonization at ICU admission.

Methods: This was a post-hoc analysis of a prospectively collected cohort study. Adult ICU patients with a length of stay of $\geq 48 \mathrm{~h}$ were included and assessed for microbiologically confirmed PA ICU pneumonia. Multivariate survival analysis was performed, including the covariates age, gender, PA colonization at ICU admission, ICU admission specialty and mechanical ventilation at ICU admission, while taking into account the effect of competing risks.

Results: We included 5093 patients, 2447 (48\%) were tested for colonization; of those 226 (9.2\%) were PA colonized at ICU admission. The incidence of PA ICU pneumonia was 1.34\% $(n=68)$. PA colonization was an independent risk factor (subdistribution hazard ratio [SHR] 8.8; 95\% confidence interval [CI] 4.9-15.7), as was mechanical ventilation (SHR 5.3, 95\% Cl 2.7-10.6).

Conclusion: In this study the incidence of P. aeruginosa ICU pneumonia was 1.34\%. Hazard ratios for PA colonized patients compared to non-colonized to develop PA ICU pneumonia were 8.8. The high risk associated with P. aeruginosa colonization for subsequent infection may offer a target for future interventions.
\end{abstract}

\section{Introduction}

P. aeruginosa (PA) is a frequently occurring nosocomial pathogen, causing potentially life threating infections, one of them being Intensive Care Unit (ICU) pneumonia, or pneumonia acquired while hospitalized on the ICU $[1,2]$. PA colonization might be a risk factor for PA ICU pneumonia, but the bacterium may also be an innocent bystander in patients with pneumonia caused by another pathogen $[1,3,4]$. The association between PA carriage on ICU admission and the occurrence of PA ICU pneumonia remains relatively unexplored.

\section{Objective}

To estimate the incidence of PA ICU pneumonia and its independent association with PA colonization at ICU admission.

\footnotetext{
* Correspondence: f.p.paling@umcutrecht.nl

1 Julius Center for Health Sciences and Primary Care, University Medical

Center Utrecht, P.O. Box 85500, Utrecht 3508 GA, The Netherlands

Full list of author information is available at the end of the article
}

\section{Methods}

This analysis was performed on the data of a prospectively collected observational cohort study, performed in a mixed ICU of a tertiary hospital in Belgium. Data on epidemiology of ICU-acquired infections were collected from January 2010 until June 2014, by means of the locally developed COSARA software application, allowing a continuous prospective registration of all infectionand antibiotic-related data [5].

Adult patients with a length of stay of $\geq 48 \mathrm{~h}$ were included; screening for PA was part of routine care in patients with an expected length of stay of $\geq 48 \mathrm{~h}$ and was based on endotracheal aspirate (ETA), oropharyngeal and/or rectal cultures. Pneumonia diagnosis was based on radiologic criteria in combination with at least 1 clinical or laboratory criterion. Confirmed PA ICU pneumonia cases are those with pneumonia occurring $\geq 48 \mathrm{~h}$ after ICU admission and laboratory isolation of PA from any location in the lower respiratory tract. All PA pneumonia diagnoses were cross-validated by trained 
research physicians. More information on the methods of this analysis are described elsewhere [6].

Patients were regarded as PA colonized at ICU admission if there was a PA positive screening sample or in case of another PA positive respiratory/skin sample on ICU admission \pm 2 days and if there was no PA infection diagnosed on these days. The incidence density of PA ICU pneumonia was determined using a Cox survival analysis that allows controlling for competing events for the occurrence of ICU pneumonia, in this case ICU discharge/death without ICU pneumonia. The final model yielded subdistribution hazard ratios (SHRs) reflecting the relative effect estimates that account for competing events and the other covariates included in the model. The included covariates were age (as a continuous variable), gender, PA colonization at ICU admission, ICU admission specialty (medical vs. surgical) and mechanical ventilation at ICU admission.

\section{Results}

Data were collected from 5093 patients, of whom baseline characteristics can be found in Table 1. A total of 2447 patients (48\%) were tested for PA colonization at ICU admission; of those 226 (9.2\%) were PA colonized. A total of 675 (13.3) patients developed ICU pneumonia. Microbiologically confirmed PA ICU pneumonia occurred in 68 patients (1.34\%). In PA colonized patients PA ICU pneumonia occurred in $9.3 \%(n=21)$; in confirmed non-

Table 1 Baseline characteristics and subdistribution hazard ratio (SHR) for $P$. aeruginosa ICU pneumonia

\begin{tabular}{|c|c|c|c|}
\hline & $\begin{array}{l}N(\%) \text { or } \\
\text { mean (SD) }\end{array}$ & $\operatorname{SHR}(95 \% \mathrm{Cl})$ & $p$ \\
\hline Gender: female ${ }^{a}$ & 1915 (37.6) & $0.73(0.43-1.24)$ & 0.24 \\
\hline Age $^{b}$ & $59.4(16.1)$ & $0.99(0.98-1.01)$ & 0.43 \\
\hline Length of stay in days & $9.1(11.7)$ & - & - \\
\hline Median & 5.0 & & \\
\hline Medical admission ${ }^{c}$ & $2176(42.7)$ & $1.34(0.82-2.20)$ & 0.24 \\
\hline \multicolumn{4}{|l|}{$\begin{array}{l}\text { Colonization status at } \\
\text { ICU admission }\end{array}$} \\
\hline$-P A-$ & $2221(43.6)$ & ref & ref \\
\hline$-P A+$ & $226(4.4)$ & $8.84(4.96-15.74)$ & $<0.001^{*}$ \\
\hline - Unknown/missing & $2645(51.9)$ & $1.04(0.58-1.86)$ & 0.89 \\
\hline ICU mortality & $691(13.6)$ & - & - \\
\hline $\begin{array}{l}\text { Mechanical ventilation at ICU } \\
\text { admission }\end{array}$ & $2591(50.9)$ & $5.2(2.70-10.47)$ & $<0.001^{*}$ \\
\hline ICU pneumonia & $675(13.3)$ & - & - \\
\hline - PA & $68(1.3)$ & & \\
\hline - other confirmed pathogen & $347(6.8)$ & & \\
\hline - unknown pathogen & $260(5.1)$ & & \\
\hline
\end{tabular}

colonized it occurred in $1.1 \%(n=25)$. The median time to PA ICU pneumonia was 7 days. PA colonization was a risk factor for the development of PA ICU pneumonia with a cause-specific hazard ratio (CSHR) of 9.6 (95\% CI 5.3$17.2, p<0.001)$. Mechanical ventilation at ICU admission was associated with higher CSHR for developing PA ICU pneumonia (CSHR 2.9; 95\% CI 1.4-6.0; $p=0.004$ ). After accounting for competing events, PA colonization at admission remained a risk factor for the development of PA ICU-pneumonia (SHR 8.8, 95\% CI 5.0-15.7, $p<0.001$, Table 1, Fig. 1), as was mechanical ventilation at ICU admission (SHR 5.3, 95\% CI 2.7-10.5, $p<0.001$ ).

\section{Discussion}

In this study PA colonized ICU patients with a length of stay of $\geq 48 \mathrm{~h}$ had an almost nine times higher risk of developing PA ICU pneumonia than non-colonized patients. Studies that investigate PA colonization as a risk factor for subsequent PA infection are very scarce, and they do not perform multivariate time-to-event analysis in combination with competing risk analyses [3, 4, 7-9].

This study has several limitations, one of them being a single-center study, another being the fact that only half of the patients were tested for PA colonization at ICU admission. Reasons for not testing included the anticipated short stay on ICU for post-surgical patients. Unfortunately, reasons for admission were not recorded and thus we cannot validate this explanation. A second draw-back is the relatively high number of pneumonias caused by unknown pathogens. We cannot rule out that these were caused by (non-cultured) $P$. aeruginosa. However, we performed a sensitivity analyses taking into account pneumonias caused by other and unknown

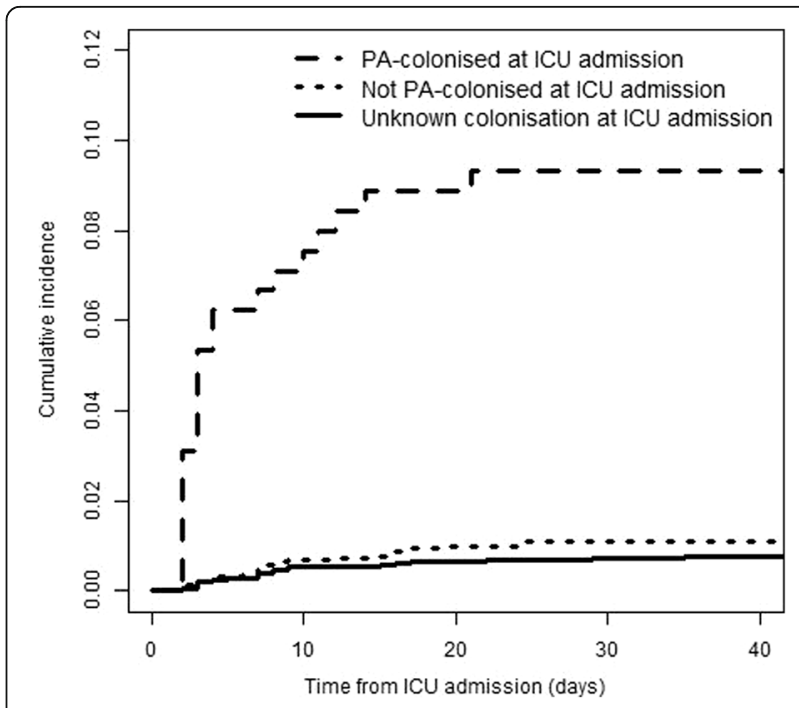

Fig. 1 Cumulative incidence function. Cumulative risk of acquiring $P$. aeruginosa ICU pneumonia 
pathogens as competing events, to assess if this changed our final estimates. This was not the case.

Despite the limitations, this study suggests that previous PA colonization contributes to the development of PA ICU pneumonia. Identifying patients at higher risk for developing subsequent infection is important in case that preventive medication becomes available, but also when empirical therapy needs to be started.

\section{Conclusion}

In this study the incidence of $P$. aeruginosa ICU pneumonia was $1.34 \%$. Hazard ratios for PA colonized patients compared to non-colonized to develop PA ICU pneumonia were 8.8 .

\section{Acknowledgments}

Not applicable.

\section{Funding}

This study was funded by the COMBACTE Consortium, which in turn was funded by Innovative Medicines Initiative Joint Undertaking (grant no. 115523).

\section{Availability of data materials}

The data that support the findings of this study are available from PD but restrictions apply to the availability of these data, which were used under license for the current study, and so are not publicly available. Data are however available from the authors upon reasonable request and with permission of PD

\section{Authors' contributions}

FP analyzed and interpreted the patient data, and wrote the manuscript. MW was a major contributor in the analysis and interpretation of the patient data. PD and $\mathrm{LdB}$ were responsible for data collection. All authors were major contributors in writing the manuscript. All authors read and approved the final manuscript.

\section{Competing interests}

FS is an employee of AstraZeneca, LP. The other authors declare that they have no conflict of interest.

\section{Consent for publication}

Not applicable.

\section{Ethics approval and consent to participate}

The independent medical ethics committee in Ghent waived the need for both informed consent and full ethical review of this post-hoc analysis. For this type of study formal consent is not required.

\section{Publisher's Note}

Springer Nature remains neutral with regard to jurisdictional claims in published maps and institutional affiliations.

\footnotetext{
Author details

1 Julius Center for Health Sciences and Primary Care, University Medical Center Utrecht, P.O. Box 85500, Utrecht 3508 GA, The Netherlands. ${ }^{2}$ Institute for Medical Biometry and Statistics, University Medical Center Freiburg, Freiburg, Germany. ${ }^{3}$ Department of Intensive Care Medicine, University Hospital of Ghent, Ghent, Belgium. ${ }^{4}$ AstraZeneca LP, Gaithersburg, MD, USA. ${ }^{5}$ Department of Medical Microbiology, University Medical Center Utrecht, Utrecht, The Netherlands.
}

Received: 30 January 2017 Accepted: 12 April 2017

Published online: 20 April 2017

\section{References}

1. Fujitani S, Sun H-Y, Yu VL, Weingarten JA. Pneumonia due to Pseudomonas aeruginosa: part I: epidemiology, clinical diagnosis, and source. Chest. 2011; 139(4):909-19.

2. Gaynes R, Edwards JR, System NNIS. Overview of nosocomial infections caused by gram-negative bacilli. Clin Infect Dis. 2005;41(6):848-54.

3. Kollef MH, Chastre J, Fagon J-Y, François B, Niederman MS, Rello J, Torres A, Vincent J-L, Wunderink RG, Go KW, Rehm C. Global prospective epidemiologic and surveillance study of ventilator-associated pneumonia due to Pseudomonas aeruginosa*. Crit Care Med. 2014;42(10):2178-87.

4. Fernández-Barat L, Ferrer M, De Rosa F, Gabarrús A, Esperatti M, Terraneo S, Rinaudo M, Li Bassi G, Torres A. Intensive care unit-acquired pneumonia due to Pseudomonas aeruginosa with and without multidrug resistance. J Infect. 2017;74(2):142-52.

5. De Bus L, Diet G, Gadeyne B, Leroux-Roels I, Claeys G, Steurbaut K, Benoit D, De Turck F, Decruyenaere J, Depuydt P. Validity analysis of a unique infection surveillance system in the intensive care unit by analysis of a data warehouse built through a workflow-integrated software application. J Hosp Infect. 2014;87(3):159-64.

6. Paling FP, Wolkewitz M, Bode LGM, Klein Klouwenberg PMC, Ong DSY, Depuydt P, De Bus L, Sifakis F, Bonten MJM, Kluytmans JAJW. Staphylococcus aureus colonization at ICU admission as a risk factor for developing S. aureus ICU pneumonia. Clin Microbiol Infect. 2017;23(1):49. e9-49.e14.

7. Harris AD, Jackson SS, Robinson G, Pineles L, Leekha S, Thom KA, Wang Y, Doll M, Pettigrew MM, Johnson JK. Pseudomonas aeruginosa Colonization in the Intensive Care Unit: Prevalence, Risk Factors, and Clinical Outcomes. Infect Control Hosp Epidemiol. 2016:37(5):544-8.

8. Venier AG, Gruson D, Lavigne T, Jarno P, L'hériteau F, Coignard B, Savey A Rogues AM. Identifying new risk factors for Pseudomonas aeruginosa pneumonia in intensive care units: experience of the French national surveillance, REA-RAISIN. J Hosp Infect. 2011;79(1):44-8.

9. Vallés J, Mariscal D, Cortés P, Coll P, Villagrá A, Díaz E, Artigas A, Rello J. Patterns of colonization by Pseudomonas aeruginosa in intubated patients: a 3-year prospective study of 1,607 isolates using pulsed-field gel electrophoresis with implications for prevention of ventilator-associated pneumonia. Intensive Care Med. 2004;30(9):1768-75.
Submit your next manuscript to BioMed Central and we will help you at every step:

- We accept pre-submission inquiries

- Our selector tool helps you to find the most relevant journal

- We provide round the clock customer support

- Convenient online submission

- Thorough peer review

- Inclusion in PubMed and all major indexing services

- Maximum visibility for your research

Submit your manuscript at www.biomedcentral.com/submit
) Biomed Central 